\title{
Cost-Effective Housing Technology with Carbon Neutral Blocks
}

\author{
Narsing Rao Sudom ${ }^{*}$, and Kishore Ravande ${ }^{2}$ \\ ${ }^{1}$ Government Polytechnic Masabtank, Hyderabad, Telangana, India. \\ ${ }^{2}$ MIT-ADT University, Pune, Maharastra, India.
}

\begin{abstract}
Conventional materials are considered to be major contributors of Green House Gas (GHG) emissions. New cost effective technologies for housing is, therefore, a need of the hour. To make mass housing cost effective in shortest possible time, each of the housing components has to be optimized for cost and production time. Disposal of fly ash is posing a great threat for its disposal problem. There is a dire necessity for alternate materials replacing conventional costly material with cost effective and environmental friendly materials making them energy efficient. This paper presents the technology and advantages of construction of cost effective and energy efficient construction using the developed Carbon Neutral Soil-Cement Fly Ash (SCF) blocks. Construction methods adopted were Arch foundation, Rat-Trap bond using SCF blocks for masonry, precast SCF block Lintel elements and partially precast SCF Slab Panels for flooring/roofing. Overall Cost to the extent of $42 \%$ can be saved using this cost effective construction technology over the conventional method. Energy of the buildingcan be drastically brought down from. $36.39 \mathrm{GJ}\left(4.2 \mathrm{~T}\right.$ of $\left.\mathrm{CO}^{2}\right)$ for conventional construction to $9.51 \mathrm{GJ}$ (1.33T of $\mathrm{CO}^{2}$ ) for cost effective construction. Energy to the extent of $74 \%$ can be saved using this Technology.
\end{abstract}

\section{Introduction}

Housing shortage is the major problem faced by the developing countries. Migration of rural people to urban areas has increased enormously and compelled them to live in unauthorized accommodation and slums. Nearly 38 million rural housing units are required for additional population during next decade [1]. Development of soilcement-fly ash (SCF) blocks and all relevant building components using SCF blocks is an effective solution to meet the challenge of providing cost effective mass housing. Soil is the most abundant and cheaply available low enrgy material traditionally used for construction of houses. It is also known fact, that traditional bricks are manufactured from the locally available suitable soil followed by baking (burning) to develop the desired strength. While on one hand burning of bricks causes air pollution, on the other hand, millions of tones of unutilized fly ash produced by industries pose great threat to the environment. Thus, there is a need to overcome these environmental related challenges while meeting the demand for mass housing.

\section{Need for the Present Work}

Adequate Shelter is a basic human need, yet most of the urban population in developing countries still lives in spontaneous settlements as they cannot afford the high cost of building materials. There is lagging in Mass housing programmes due to high costs of conventional building materials. They are also high energy intensive and are becoming scarce giving rise to threats to mass housing. Disposal of waste materials of the industries is becoming a major problem. Hence the need of the hour is to replace conventional construction materials by alternate energy efficient materials with emphasis on alternate technologies. To meet the unprecedented demand for mass housing there is a huge requirement of building blocks. Burnt clay bricks pose threat to environment due to emission of carbon dioxide due to burning of bricks. It is estimated that $24 \%$ of green house gas (GHG) emissions [1] is contributed by the construction industry in India. Also, millions of tons of unutilized fly ash produced by industries pose great threat to environment. Thus, the need of the hour is to overcome these environmental related challenges by developing bricks/building blocks which are produced by using local soil, cement, fly ash and water curing without any baking or burning. The present paper disseminates developed SCF blocks which are in turn utilized in casting of cost-effective building components with an emphasis on optimizing construction time. 


\section{Carbon Neutral Soil-Cement-Fly Ash (SCF) Blocks}

New cost effective and energy efficient technologies for housing are essential to cope up with the ever increasing demand of housing and reduction in carbon dioxide emissions. Cement being the main component of construction activity, construction industry is considered to be the major contributor of Green House Gas emissions. Hence a block had been developed to overcome the above mentioned drawbacks and resulted in the development of Soil-Cement-Fly ash (SCF) blocks which are cost effective and energy efficient. This sustained research work has resulted in to a product with strength and durability, besides making it carbon neutral.

\subsection{Method of Manufacture of SCF Blocks}

The process of making these blocks are as under: Any locally available soil, other than black cotton soil, can be used for the production of masonry blocks with suitable modification in grading of soil to derive maximum density. Ideally, the particle size distribution in a soil sample should match the Fuller curve[2]. Hence, the soil proposed to be used in production of blocks was made up for the deficiencies in particle sizes so as to bring it close to the Fuller curve requirement. 50 to $85 \%$ of the locally available soil is reconstituted by blending and mixed with 1 to $5 \%$ cement and 5 to $50 \%$ of fly ash. Blending of different soils with fly ash was done to achieve the grading of blended soil which closely matches the Fuller's curve of minimum voids. Optimum fly ash content to be added in the mix was determined from experimental work.

The method of blending was computerized and adopted to arrive at the proportions of natural soils/manufactured fine aggregate and fly ash to be blended. Required quantity of SCF mixture was filled in the mould in three layers and the whole assembly of the mould was placed on the machine and was operated to effect the vibrocompaction to get maximum density by a vibrocompacting block making machine. The mould assembly was demounted and the SCF blocks were demoulded. Standard SCF block specimens of size $215 \times 100 \times 75 \mathrm{~mm}$ were prepared and cured. The SCF blocks were then subjected to compressive strength test and durability test. The strength and Durability Characteristics of SCF Blocks are given in Table 1. There is significant increase in the ratio of wet to dry strength of SCF blocks and reduction in loss of their weight on wetting and drying test with increase in fly ash content, thus reflecting the improved durability of blocks.

This may be attributed to addition of fly ash which fills in micro pores and proper grading of blended soil resulting in increased density followed by strength and durability $[3,4]$.

There was extensive studies carried out on energy values of SCF blocks. SCF blocks so developed are carbon neutral (viz. the energy value is zero) with addition of fly ash and cement, whereas the energy content of burnt clay brick is $4.35 \mathrm{MJ}$ per brick.
Table 1. Strength and Durability Characteristics of SCF Blocks

\begin{tabular}{|c|c|c|c|}
\hline Properties & Mean & $\begin{array}{c}\text { Standard } \\
\text { deviation }\end{array}$ & $\begin{array}{c}\text { Coefficient } \\
\text { of } \\
\text { variation }\end{array}$ \\
\hline $\begin{array}{c}\text { Wet } \\
\text { compressive } \\
\text { strength } \\
\text { (MPa) }\end{array}$ & 5.22 & 0.68 & $13 \%$ \\
\hline $\begin{array}{c}\text { Water } \\
\text { absorption } \\
\text { (MPa) }\end{array}$ & 11.92 & 0.75 & $6.27 \%$ \\
\hline $\begin{array}{c}\text { Durability on } \\
\text { alternate } \\
\text { wetting and } \\
\text { drying (\% } \\
\text { reduction in } \\
\text { weight) }\end{array}$ & 0.35 & 0.028 & $8.07 \%$ \\
\hline
\end{tabular}

The cost of manufacture of each SCF block is worked out at Rs.4-00 and details are shown in Table 2. SCF bricks are $63 \%$ cheaper than conventional burnt clay bricks at prevailing market rate.

Table 2. Cost of Manufacture of SCF Brick

\begin{tabular}{|c|c|c|c|}
\hline $\begin{array}{c}\text { Description } \\
\text { of Item }\end{array}$ & $\begin{array}{c}\text { Amount } \\
\text { (Rs.) }\end{array}$ & $\begin{array}{c}\text { Description of } \\
\text { Item }\end{array}$ & $\begin{array}{c}\text { Amount } \\
\text { (Rs.) }\end{array}$ \\
\hline Soil & 0.43 & Total & 2.27 \\
\hline Cement & 0.85 & Misc @ 28\% & 0.64 \\
\hline Fly ash & 0.22 & Profit @ 20\% & 0.45 \\
\hline Labour & 0.67 & Transport & 0.60 \\
\hline Power & 0.10 & $\begin{array}{c}\text { Final cost of } \\
\text { each brick }\end{array}$ & 3.96 \\
\hline \multicolumn{4}{|c|}{ Rounded 4.00* } \\
\hline
\end{tabular}

$* 63 \%$ cheaper than conventional burnt clay brick

\subsubsection{Embodied energy of SCF blocks}

Embodied energy content of SCF blocks dependent upon cement content and fly ash addition. The embodied energy due to addition of cement is $862.5 \mathrm{MJ}$. In addition $21 \mathrm{MJ}$ of energy is required for operating block making machine having 1 H.P. Transport of the soil to the casting yard consumes $67.5 \mathrm{MJ}$. Fly ash addition plays a dual role viz., becomes cementitious in the presence of excess lime and has energy saving value of 6.17 MJ per $\mathrm{kg}$. Fly ash to the extent of five percent replaces cement and remaining five percent is taken as otherwise land filled. The energy values of fly ash replacing cement and land filling are $-5.966 \mathrm{MJ} / \mathrm{kg}$ and $0.617 \mathrm{MJ} / \mathrm{kg}$ respectively as specified by EPA [5]. Considering the energy values due to energy intensive cement and energy savings associated with fly ash addition, the net energy value of the block is $-0.036 \mathrm{MJ}$ or $-0.011 \mathrm{MJ} / \mathrm{kg}$. Since there are no emissions of GHG with SCF block, the block is regarded as Carbon Neutral[6].

\subsubsection{Abatement of $\mathrm{CO} 2$}

If SCF blocks are replaced by burnt clay bricks to the extent 100 billion bricks, the CO2 emission reductions would be 43.12 million Tons. In addition, the reduction 
in GHG emissions would be 7.12 million Tons due to better surface of wall requiring no plastering and thus resulting in further saving of cement.

\section{Cost-Effectiveness for Sub- Structure}

\subsection{Arch Foundation}

This foundation was constructed for the research work taking into consideration economy and energy efficiency (low carbon material). Arch foundations are adopted for soils of low bearing capacity with semi-circular or segmental curves so that the ends of arches rest on side abutments and they in turn supported on deeper hard stratum. Since these foundations are cheaper than conventional construction they are best suited for costeffective housing in hard stratum at shallow depths.

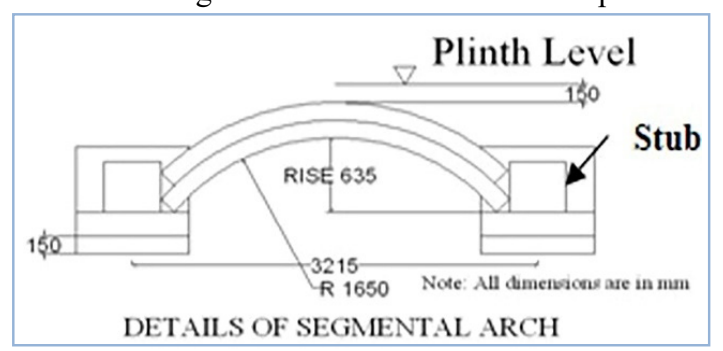

Fig. 1. Details of Arch Foundation

\subsubsection{Arch Foundation Construction}

Stubs are compression members to receive thrust from arches. After excavating a trench of size $1 \mathrm{~m} \times 1 \mathrm{~m} \times 1 \mathrm{~m}$, P.C.C. of proportion $(1: 5: 10)$ was laid at the bottom to a thickness of $150 \mathrm{~mm}$ and compacted well to make a levelled surface. First footing consisting of CRS in $\mathrm{CM}(1: 6)$ and constructed to a thickness of $200 \mathrm{~mm}$. The CRS stubs of size $500 \mathrm{~mm}$ x $500 \mathrm{~mm}$ were constructed to a height of $500 \mathrm{~mm}$ above first footing. Segmental arches using cement concrete blocks in CM (1:4) were constructed with a span of $2300 \mathrm{~mm}$ and a rise of 635 $\mathrm{mm}$. Bottom profile of the arch was made with CRS masonry and top surface was made smooth to receive cement concrete blocks. To prevent moisture from entering in to masonry, R.C.C damp proof course of 75 $\mathrm{mm}$ thick was cast. Details of arch foundation are shown in Fig 1 and Fig 2 .

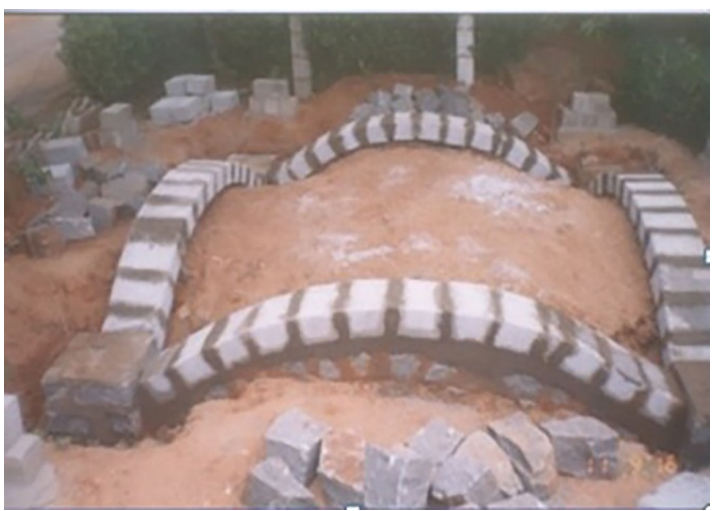

Fig. 2. Arch Foundation Construction in progress

\subsection{Soil Cement Fly Ash (SCF) Mix Foundation}

In case the SCF mix which is used for in situ work such as in foundation, there are no energy values associated with transportation and also no casting work takes place. On incorporating above two values, the net energy value of SCF mix would be $-0.039 \mathrm{MJ} / \mathrm{kg}$. Since there are no emissions of GHG with SCF mix, the mix also is regarded as Carbon Neutral.

\subsubsection{SCF Mix Foundation Construction}

This foundation is an alternative to cost-effective arch foundation. This type of foundation is similar to spread foundation, except that the excavated trench is filled and rammed with SCF mix. The soil which is excavated from the trench foundation is sieved and then measured at the same time on the side of the trench. Blending is resorted to as discussed in section 3.1. The mix should be calculated for 1 bag of cement per mix. A team of workers mix and ram manually or mechanically. Usually the top level of the foundation is at the level of the original ground. The section of the foundation should normally be square. Two-floor building section of foundation should be $75 \mathrm{~cm} \mathrm{x} 75 \mathrm{~cm}$. This mix is not only Carbon Neutral but also cost-effective.

\section{Cost-Effective Housing Technology for Super Structure}

\subsection{Rat-trap Bond Masonry}

In this bond of brick work, bricks are laid on edge with alternate rowlocks (brick on edge showing its breadth and height)and shiners (brick on edge showing its length and height) leaving $65 \mathrm{~mm}$ gap $(215-2 \times 75=65 \mathrm{~mm})$ in between bricks. In this bond each alternate course begins with two rowlocks followed by a shiner.

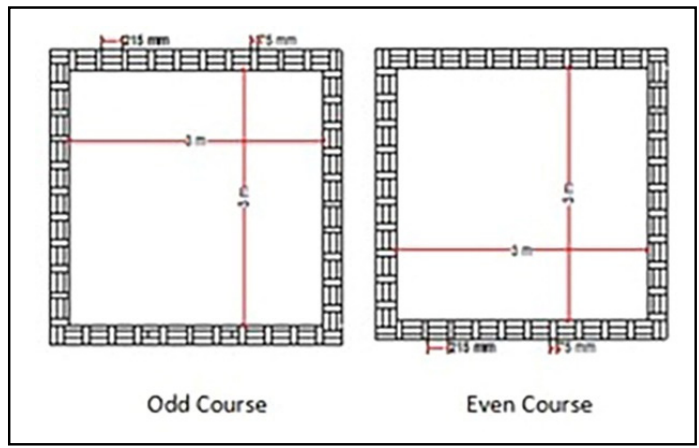

Fig 3 Plans of Odd \& Even Courses in Rat-Trap Bond

The intermediate course begins with a shiner succeeded by a rowlock as shown in Fig. 3. Overall wall thickness of 215 can be maintained with around $21 \%$ cavities. Economy to the extent of $21 \%$ in bricks and $25 \%$ in cement mortar can be achieved (lesser number of joints). 
This bond is simple to implement and can be employed for fast track construction and has thermal and acoustical comfort due to internal cavity. Plastering can be avoided since SCF blocks have sharp and straight edges that enhance beauty of the building. Details of construction of rat-trap bond masonry is shown Fig. 4.

\subsection{Provision of Vertical Reinforcement in Rat- trap Bond}

\subsubsection{Quetta bond}

This bond is adopted when it is necessary to provide vertical reinforcement in walls for areas subjected to earth tremors. Minimum thickness of wall in this case is one and half brick. With the adoption of this bond, quarter brick by half brick pockets, which are continuous through full height of the wall, are formed along the length of the wall. In these pockets steel rods are placed, and pockets are filled up with cement concrete as the work proceeds.

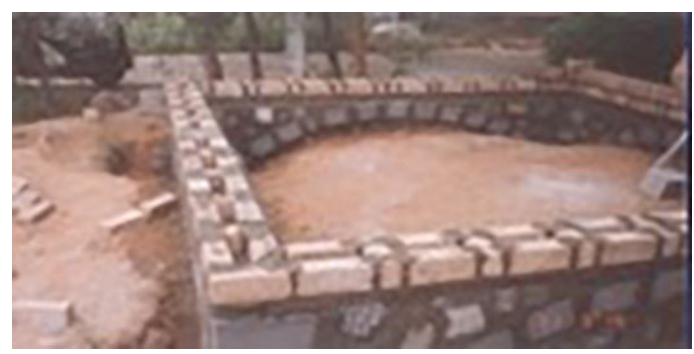

Fig. 4. Rattrap bond brick masonry

\subsubsection{Vertical reinforcement bars}

Bureau of Indian Standards (BIE) suggests provision of vertical reinforcement at corners of walls, junctions of walls, jambs of windows and jambs of doors. Code specifies use of Quetta bond for vertical reinforcement in walls for areas subjected to earth tremors. Since Quetta bond is employed for one and half thick brick wall, for one brick thick wall the Rattrap bond is best suited to provide vertical reinforcement in cavities $(65 \mathrm{~mm} \times 65$ $\mathrm{mm}$ ) of walls for areas subjected to earthquake.

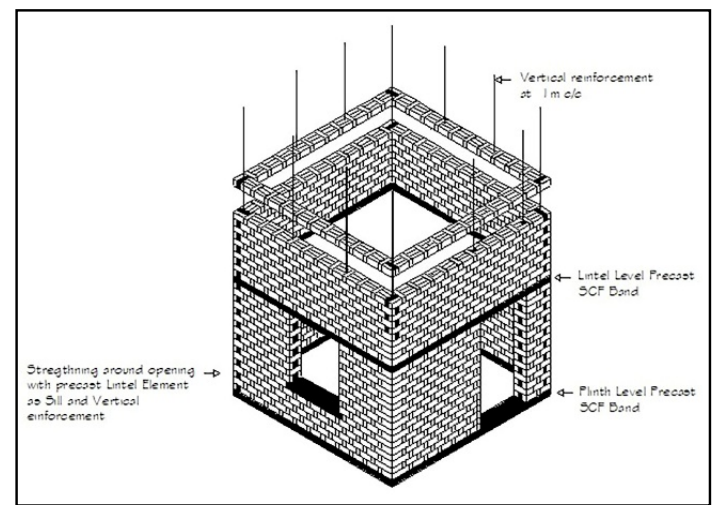

Fig. 5. Earthquake Provisions in SCF block Rattrap bond Masonry and Horizontal bands ( DPC/Lintel/Sill)

\subsubsection{Embodied Energy of Conventional Masonry Vis-Ä-Vis SCF Block Masonry}

The embodied energy of burnt clay brick masonry is $2573.2 \mathrm{MJ} / \mathrm{m}^{3}$ whereas it is $193.1 \mathrm{MJ} / \mathrm{m}^{3}$ with $\mathrm{SCF}$ block masonry. Embodied Energy of SCF block masonry drastically reduced due to Carbon Neutral block and is only $8 \%$ of the burnt clay brick masonry [7].

\subsection{Precast SCF Lintel}

As soon as the SCF block masonry construction reaches lintel level, precast lintels will be placed over the door and window openings and masonry work is further continued above the lintel level. Construction features of SCF lintels are similar to that of partially precast SCF Slab Panels. Fig 6 shows the details of lintel over door opening. This structural element can be used as Plinth band (as DPC), window Sill level element which becomes integral part of vertical reinforcement of openings and lintel level band for earthquake resistant design as shown in Fig. 5. This element is designed in parts of $1.0 \mathrm{~m}$ span and joined together.

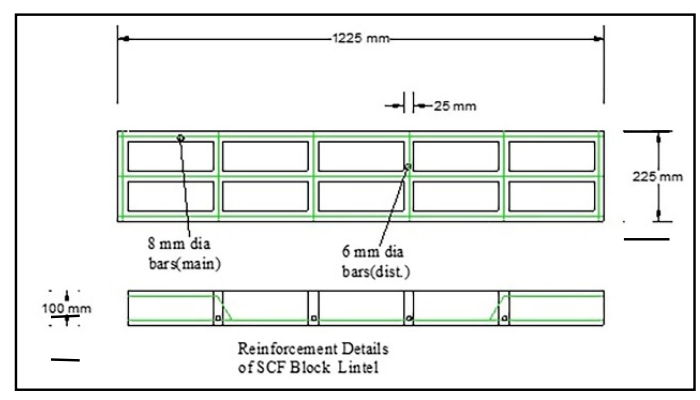

Fig. 6. Details Of Reinforced S.C.F Block Lintel of span $1225 \mathrm{~mm}$

\subsection{Partially Precast SCF Slab Panels for Floor/Roof}

For casting purpose a wooden mould was prepared using wooden pieces of cross section dimensions of $75 \mathrm{~mm} \mathrm{x}$ $50 \mathrm{~mm}$ to prepare the mould of internal dimensions of $1805 \mathrm{~mm}$ x $350 \mathrm{~mm} \times 75 \mathrm{~mm}$.

The wooden mould with an opening at the base was kept on a leveled ground having thin layer of sand. The bricks were wetted and arranged in the mould with a $50 \mathrm{~mm}$ gap between them. Steel reinforcement cage $(8 \mathrm{~mm}$ diameter main reinforcement and $6 \mathrm{~mm}$ diameter distribution reinforcement) was inserted in the gap of assembly of bricks with a provision of $15 \mathrm{~mm}$ cover. M20 grade concrete was then poured in the gaps and finished flush with the bricks. After demoulding, the slab panel was cured for 14 days in water and 14 days in air. The required number of slab panels were made ready. Figure 9 shows arrangement of blocks and reinforcement in a slab panel. The required number of slab panels of dimensions $1805 \mathrm{~mm}$ x $350 \mathrm{~mm}$ x $75 \mathrm{~mm}$ were produced for construction of a assembled slab system over a room 
of size $3 \mathrm{~m} \times 3 \mathrm{~m}$ and tested it for deflection recovery test (prototype testing).

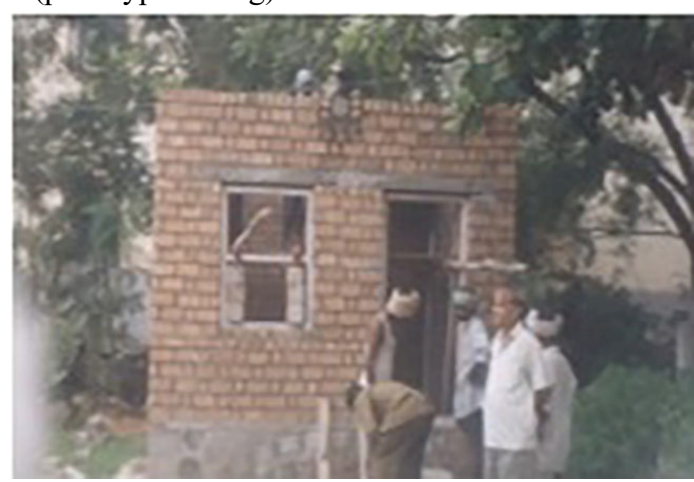

Fig. 7. R.C Joist Supported over Bearing Walls

\subsubsection{Partially precast RC Beam}

A partially precast beam was cast to reduce span of SCF slab panel. A mild steel mould of $150 \mathrm{~mm}$ x $150 \mathrm{~mm}$ cross sectional dimensions and length equal to $3 \mathrm{~m}$ (room width) was used for moulding a partially precast reinforced cement concrete joist. After placing the mould on a levelled surface, the reinforcement cage was placed in the mould with a provision of $25 \mathrm{~mm}$ cover. Steel reinforcement provided for the partially precast joist was designed as per the procedure laid down in IS $14142-1994$ [8]. The concrete was poured in the mould and compacted properly. After demoulding, the joist was cured for 14 days in water and for 14 days in air prior to placing it over SCF block masonry wall for assembly of slab panels as shown in fig.7.

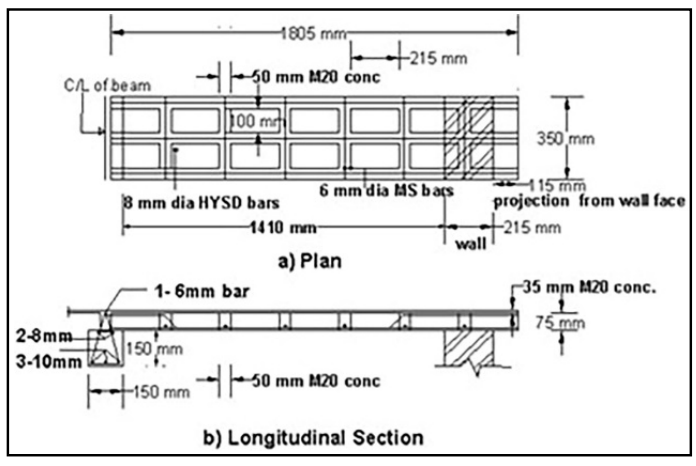

Fig. 8. Details of Reinforced S.C.F Block Slab Panel of length $1805 \mathrm{~mm}$

\subsubsection{Arrangement of SCF slab panels over the RC Joist and wall}

The partially precast joist (beam) was placed over SCF block wall with a $15 \mathrm{~mm}$ thick cement-coarse sand (1:4) mortar beneath it. The alignment/ placement of joist was checked and then propped at one third span locations. The brick panels with overall size of $1805 \mathrm{~mm} \times 350$ $\mathrm{mm} \times 75 \mathrm{~mm}$, shown in Fig. 8, were placed over the joists/wall, side by side after laying a $6 \mathrm{~mm}$ thick layer of cement coarse sand (1:4) mortar over the joists/walls.
Arrangement of brick panels over masonry wall and precast joist (beam) is shown in Fig. 9. The gaps between the panels were filled up with rich mortar. Shrinkage and temperature reinforcement of $10 \mathrm{~g} \mathrm{x} 10 \mathrm{~g}$ $-100 \mathrm{~mm} \times 100 \mathrm{~mm}$ welded wire mesh was placed over the panels. A $35 \mathrm{~mm}$ thick screed concrete layer was poured on the top of the assembled slab panels. The roof was finished with a floating coat of $1: 3$ cement fine sand mortar of $6 \mathrm{~mm}$ thickness just after laying the in-situ concrete and cured for two weeks. The prefabricated SCF brick slab panel was designed as simply supported between a joist and a wall as per IS: 14142- 1994[8]. Extensive deflection recovery test was carried out by K. Ravande and N. Sudom [9] as specified in clause 17.6.3 of IS: 456-2000 [10] on the entire assembly of SCF slab panels and joist provided over a room of dimensions $3 \mathrm{mx} 3 \mathrm{~m}$.

\subsubsection{Embodied Energy of Conventional RCC Slab and SCF Slab Panels}

The embodied energy of conventional RCC (Reinforced Cement Concrete) slab is worked out to be $272.32 \mathrm{MJ} / \mathrm{m} 3$ whereas the embodied energy with SCF block slab panel [7] is $2539.47 \mathrm{MJ} / \mathrm{m} 3$. The energy content of SCF slab is $59 \%$ of the energy content of the RCC slab.

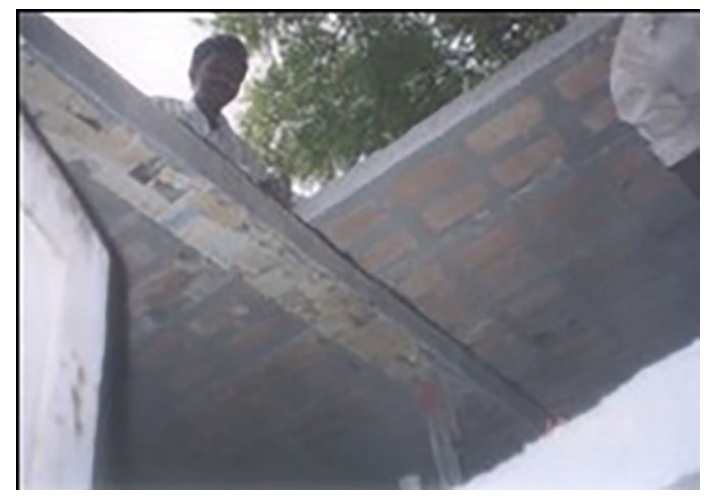

Fig. 9. Details of Reinforced S.C.F Block Slab panel supported on RC joist and wall

\section{Cost Analysis}

Cost comparison of the Cost-effective housing using CNB vis-a-vis the conventional construction is given in Table 3 and is evident that there is a saving of $42 \%$ by adopting CNB with partial prefabrication. It is evident from table 2 that the cost of each SCF Block worked out at Rs.4-00. For rate analysis, Telangana State Common Standard Schedule of rates of 2019-20 were considered. Area allowance of $40 \%$ in GHMC Limit, Hyderabad, Telangana was also taken into consideration. The plinth area rate of cost-effective construction using SCF blocks works out to be Rs.1268/sft or Rs. $13640 / \mathrm{m}^{2}$ compared to conventional cost of Rs.2189/sft or Rs. 23554/. Saving to extent of $42 \%$ is achived by adopting cost effective construction with a plinth area of 126.6 sq.ft or 11.77 $\mathrm{m}^{2}$. If benefitiary directly under takes construction of the 
residence, the plinth area rate works out to be Rs.600-00 per sft or Rs.6456-00 per $\mathrm{m}^{2}$ without any agency.

\section{Embodied Energy of Conventional Load Bearing and SCF Load Bearing Construction}

The embodied energy of conventional brick load bearing with RCC slab is worked out to be $36.39 \mathrm{GJ}$ for a plinth area of $16.6 \mathrm{~m}^{2}$ whereas the embodied energy with SCF block load bearing using SCF slab panels is $9.51 \mathrm{GJ}$. Energy to the extent of $74 \%$ can be saved using SCF Block Technology in the construction of a house. Carbon dioxide emissions can be brought down from $4.2 \mathrm{~T}$ for a conventional construction to $1.33 \mathrm{~T}$ for cost effective house using SCF Block Housing Technology [7].

\subsection{Saving in Cement Compared to Convention- al Construction}

In mass housing programme with a plinth area of 16.6 $\mathrm{m}^{2}$, the saving in cement with SCF blocks construction would be around $1150 \mathrm{~kg}$ compared to conventional construction. At national level considering shortage of housing in rural and urban areas at 20 million housing units the saving in cement would be 23 million Tons. The benefit arising out of saving in cement is Rs. 115 billion ( $\$ 1.65$ billion). The saving in cost due to GHG emission reduction in terms of Carbon Credits is Rs.32 Billion (\$ 460 million).

\section{Time of Construction}

With partial prefabrication and using precast units for DPC, Sill and Lintel Level the time of construction can be drastically reduced. With proper scheduling, SCF Block residence can be completed within 30 days.

\section{Climate Change Mitigation and Sustain -able Development}

GHG emission is the reason for global warming. Burnt clay bricks pose threat to environment due to emission of GHG due to burning of bricks. While construction industry cannot do away with the bricks or building blocks for meeting the housing demand, the concern for the environment, particularly embodied energy associated with the bricks and its reduction is the need of the hour. The alternate construction technologies play a vital role not only in cost reduction but also in the reduction of GHG emissions[7] and help in protection of environment which lead to sustainable development. The construction of houses using SCF block and housing elements would mitigate climate change considerably.
1. Carbon Neutral SCF blocks are alternative to energy intensive burnt clay bricks and are cost effective.

2. Construction using Carbon Neutral SCF blocks has in-built advantages to perform better against earthquake forces by providing SCF Plinth band, Sill, Lintel level band and vertical reinforcement in the masonry.

3. Construction of experimental prototype room disseminates the construction Technology and brings awareness among the end users and develop confidence to utilize the material and Technology.

4. Plastering can be completely avoided taking durability of the block into consideration. For smooth and elegancy of inside surfaces, luppum finishing to walls and plaster of paris to ceiling may be recommended instead of plastering since bricks are true and square.

5. The Construction Technology developed using Soil Cement Fly Ash blocks has resulted in significant Reduction of cost by $42 \%$ over conventional construction thus paving way for implementing mass housing projects for the benefit of poor homeless population.

\section{References}

1. Dev. Alt ,News Lr. N. Del. (2014) https://www.devalt.org/newsletter/may14/of_3.htm

2. G.Rothfuchs, Betonstrasse, 14, 12, (1939)

3. N. Del, B.I.E, Specifications for Soil Based Blocks Used in General Building Construction, IS 1725, (1982)

4. K.Ravande, N. Sudom, P. REDECON, India, 139, (2007)

5. Anne Choate, Report of U.S. Environmental Protection Agency, (2005)

6. N.Sudom, K. Ravande, P. ISEC-6, Zurich, 21, (2011).

7. N.Sudom, K. Ravande, J. Adv. Mat. R 935, 197, (2014)

8. B I E, Design and Construction of Floors and Roofs with Prefabricated Brick Panel, N. Del. IS 14142, (1994)

9. K. Ravande, N. Sudom, P. SEWC,India, 197, (2007)

10. B.I.E, Code of Practice for Plain and Reinforced Concrete, N. Del. IS 456, (2000)

\section{Conclusions}


Table 3 Cost Comparison of Cost-effective Construction with Conventional Construction

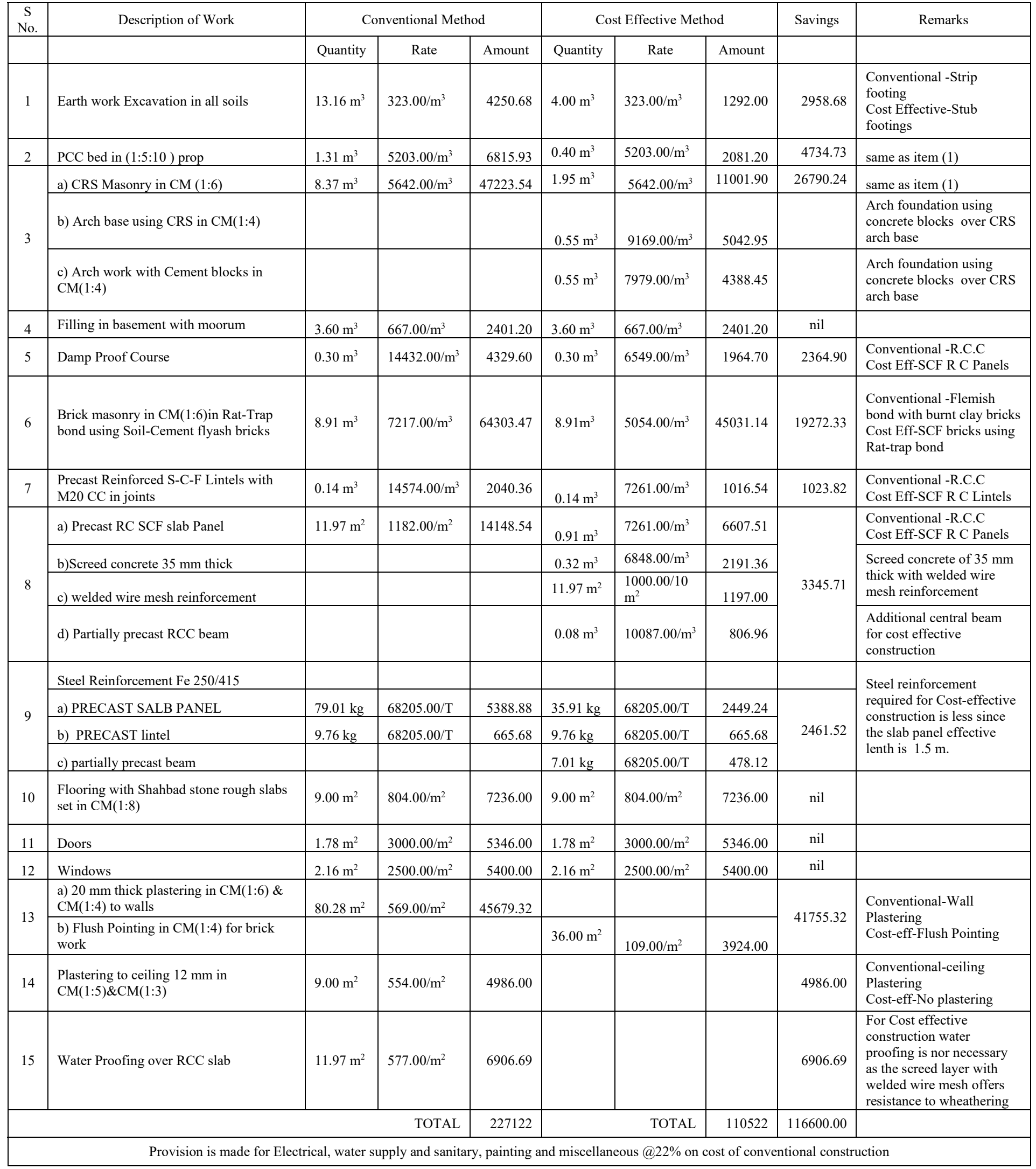

